OPEN ACCESS

Edited by:

Carla Mucignat,

University of Padua, Italy

Reviewed by:

Paul Manger

University of the Witwatersrand,

South Africa

Armen Saghatelyan,

Laval University, Canada

Paul Trombley,

Florida State University, USA

${ }^{*}$ Correspondence:

Ottorino Belluzzi

mk5@unife.it

Received: 02 December 2016 Accepted: 02 February 2017

Published: 14 February 2017

Citation:

Pignatelli $A$ and Belluzzi O (2017) Dopaminergic Neurones in the Main Olfactory Bulb: An Overview

from an Electrophysiological

Perspective.

Front. Neuroanat. 11:7. doi: 10.3389/fnana.2017.00007

\section{Dopaminergic Neurones in the Main Olfactory Bulb: An Overview from an Electrophysiological Perspective}

\author{
Angela Pignatelli and Ottorino Belluzzi * \\ Life Sciences and Biotechnology, University of Ferrara, Ferrara, Italy
}

The olfactory bulb (OB), the first center processing olfactory information, is characterized by a vigorous life-long activity-dependent plasticity responsible for a variety of odor-evoked behavioral responses. It hosts the more numerous group of dopaminergic (DA) neurones in the central nervous system, cells strategically positioned at the entry of the bulbar circuitry, directly in contact with the olfactory nerve terminals, which play a key role in odor processing and in the adaptation of the bulbar network to external conditions. Here, we focus mainly on the electrophysiological properties of DA interneurones, reviewing findings concerning their excitability profiles in adulthood and in different phases of adult neurogenesis. We also discuss dynamic changes of the DA interneurones related to environmental stimuli and their possible functional implications.

Keywords: dopaminergic neurones, olfactory bulb, electrophysiology, adult neurogenesis, experience-dependent plasticity

\section{INTRODUCTION}

Of the 11 distinct dopaminergic (DAergic) cell groups identified in the mammalian central nervous system (Dahlström and Fuxe, 1964; Felten and Sladek, 1983; Hökfelt et al., 1984; Dubach, 1994), the olfactory bulb (OB) hosts the most numerous (Guyenet and Crane, 1981; Cave and Baker, 2009) identified as A16 in the standard classification (Björklund and Dunnett, 2007).

Within the OB, DAergic neurones have been reported almost only in the most external (glomerular) layer (Halász et al., 1981), and it is generally accepted that they co-release dopamine (DA) and GABA from separate pools of vesicles (Maher and Westbrook, 2008; Borisovska et al., 2013). The glomerular layer is populated by a variety of cell types, essentially ascribable to three major classes of interneurones, i.e., periglomerular (PG), short-axon (SA) and external tufted (ET) cells. Since DA neurones are the only catecholaminergic neurones found in the OB (Kratskin and Belluzzi, 2003), they are usually recognized by the expression of tyrosine hydroxylase (TH), a rate-limiting enzyme of catecholaminergic pathway; it is estimated that $10 \%-16 \%$ of the neurones in the more external (glomerular) layer (GL) of adult animals are DAergic (McLean and Shipley, 1988; Panzanelli et al., 2007), and that they include two types of cells, PG (Kosaka et al., 1985; Gall et al., 1987) and a subpopulation of ET cells which, at difference from the tufted cells present in the external plexiform layer (EPL), are not projection neurones (Halász, 1990). Under the functional point of view, a first demonstration of the involvement of DA neurones in olfaction is provided by the impairment of olfactory discrimination in mice lacking functional dopamine receptors or transporters (Wilson and Sullivan, 1995; Tillerson et al., 2006; Taylor et al., 2009), and by the well-known observation that olfactory impairment is one of the earliest non-motor traits of Parkinson's disease (Doty, 2012), preceding the onset of motor symptoms by years. 
Bulbar DA cells are interesting under many aspects, but three characteristic in particular have attracted significant attention in the last years: first they are extremely plastic (Baker et al., 1983; Bastien-Dionne et al., 2010), second their position at the entry of the bulbar circuitry makes them obvious candidates for a significant role in the odor processing (Borisovska et al., 2013) and, third, DA cells are constantly generated throughout life (Altman, 1969; Betarbet et al., 1996; Baker et al., 2001; Winner et al., 2002; Mizrahi et al., 2006; Ventura and Goldman, 2007; Lazarini et al., 2014), an attribute that has raised further interest for the potentiality offered by neural stem cells in the germinal area (adult subventricular zone (SVZ)) as a source of autologous neuron for repopulation of the damaged areas in Parkinson's disease (Cave et al., 2014).

Many excellent studies have covered the different aspects of DA neurobiology, especially for what concern the complex interplay of transcription factors, epigenetic control and role of non-neuronal cells in orchestrating birth, migration, differentiation and maintenance of these cells in adult neurogenesis (Saino-Saito et al., 2004; Hack et al., 2005; Kohwi et al., 2005; Brill et al., 2008; Havrda et al., 2008; Flames and Hobert, 2009; Cave et al., 2010; Caiazzo et al., 2011; Banerjee et al., 2013; Marei and Ahmed, 2013; Agoston et al., 2014; Vergaño-Vera et al., 2015; Bonzano et al., 2016; Rodríguez-Traver et al., 2016).

Here we rather focused on a somewhat lesser investigated aspect, the electrophysiological properties of adult born DA neurones in the different phases of their life, and the possible implication of their excitability profiles and adult neurogenesis in odor processing.

\section{TWO MORPHOLOGICALLY DISTINCT DA NEURONES}

The bulbar DA neurones have long been known to be different in size and morphology, presenting at least two main subtypes in almost all the species examined, including humans, (Halász et al., 1981; Davis and Macrides, 1983; Hoogland and Huisman, 1999; Pignatelli et al., 2005; Kosaka and Kosaka, 2007, 2008; Liberia et al., 2012). Several reviews address the analysis of the differences classifying the two DA interneurons subtypes, according to their morphological attributes and molecular signatures, in large vs. small (Kosaka and Kosaka, 2011; Imai, 2014; Nagayama et al., 2014). Kiyokage et al. (2010) propose an alternative classification in oliglomerular vs. poliglomerular DA neurones, suggesting that all DA interneurons are SA cells (Kiyokage et al., 2010)-we direct the reader wishing to learn more on this debate to the excellent recent review of Kosaka and Kosaka (2016). Given the demonstration that many DA PG cells exhibit the molecular markers of the presence of an axonal initial segment (IS), i.e., of an axon (Chand et al., 2015), we have adopted the first classification preferring, in this short review, to maintain the focus onto the less investigated problem of the functional properties of these cells.

In mice, the two main subtypes of $\mathrm{OB}$ DA neurones have average diameters of $8.76 \pm 1.58$ and $10.69 \pm 2.70 \mu \mathrm{m}$ (Kosaka and Kosaka, 2008) and membrane capacities of $5.41 \pm 1.5$ and $10.63 \pm 3.45 \mathrm{pF}$ (Pignatelli et al., 2005). Since the distributions of dimensions and membrane capacities of the two subtypes can be best fitted by two largely superposed Gaussian curves (see Figure 6 of Kosaka and Kosaka, 2007 and Figure 1C of Pignatelli et al., 2005), in most electrophysiological experiments it has not been possible to identify beyond any reasonable doubt the specific subtype of the cell recorded in OB slices. However, an interesting functional criterion for the discrimination of large vs. small DA neurones has been adopted by the group of M.S. Grubb, based on the observation that larger DA cells present an axon, whereas the smaller one are anaxonic (Chand et al., 2015; Kosaka and Kosaka, 2016). The action potentials (AP) originating in the soma and then propagating to the dendrites (soma-dendritic, SD AP) are slightly different from the AP originating in the IS and then back-propagating to the soma, where they are recorded (IS-SD AP); this barely noticeable difference in current-clamp recorded AP becomes more evident by representing the AP in a voltage vs. rise time plot (phase plane plot), where a noticeable bump in correspondence of the Hodgkin cycle initiation marks the IS-SD nature of the AP (Figure 2Dii of Chand et al., 2015). This criterion has been adopted to discriminate axonic-large vs. anaxonic-small DA cells in in vitro cultured dissociated cell (Chand et al., 2015; Galliano and Grubb, 2016) with remarkable results. Although the complement of voltage dependent channels in the two cell types does not appear to be significantly different (Pignatelli et al., 2005), the largest cells are more excitable than the smallest one, a disparity attributable to a series of differences in their excitability profile. In particular, the largest DA cells, with respect to the smallest one have lower threshold and rheobase current, faster rising phase of the AP, higher firing frequency, and other peculiarities discussed in detail in the recent article of Chand et al. (2015).

Larger TH+ neurones, initially regarded as ET cells (Halász et al., 1981; Davis and Macrides, 1983) and later recognized as GABAergic (Kosaka and Kosaka, 2007; Panzanelli et al., 2007; Parrish-Aungst et al., 2007), are glomerular interneurones giving a substantial contribution to interglomerular connections, establishing long-range intrabulbar coordination systems. A first intrabulbar association system has been described in which mirror-symmetric isofunctional odor columns (cross-laminar ensembles of neurones impinging onto a single glomerulus) are mutually connected through a reciprocal inhibitory circuit; the assembly includes distinct population of large $\mathrm{TH}+\mathrm{ET}$ cells making synapses on the granule cells on the opposite edge of the OB (Schoenfeld et al., 1985; Lodovichi et al., 2003; Kosaka and Kosaka, 2011). Another long-range intraglomerular association system sustained by large type DA glomerular neurones would connect glomeruli ipsilaterally (Kosaka and Kosaka, 2011). Accordingly, large DA neurones in the glomerular layer have been shown to express axon initial segment (AIS) markers, absent in the small DA neurones, both in vivo (Kosaka and Kosaka, 2011) and in vitro (Chand et al., 2015; Galliano and Grubb, 2016).

Small $\mathrm{TH}+$ cells, accounting for about $85 \%$ of the bulbar DA neurones (Pignatelli et al., 2005), appear to extend their 
connection to a single glomerulus, or to few close glomeruli (Kosaka and Kosaka, 2008, 2011, 2016).

Differences among large- and small-sized $\mathrm{TH}+$ glomerular cells are also observed in the adult neurogenesis: the investigation of their birth dates has shown that large DA neurones are born only pre- and perinatally, never in adulthood, whereas the small type of DA neurones are generated also in adult periods (Kosaka et al., 1987; Vergaño-Vera et al., 2006; Bovetti et al., 2009; Kosaka and Kosaka, 2009; Galliano and Grubb, 2016).

\section{ELECTROPHYSIOLOGY OF MATURE BULBAR DA NEURONES}

DA-PG cells in the OB have been the object of electrophysiological studies (Pignatelli et al., 2005; Puopolo et al., 2005), which have provided a comprehensive description of the complex system of the voltage-dependent conductances determining their excitability profile, including the pacemaking machinery.

DA bulbar neurones present two large and five small voltagedependent conductances; all of them have been kinetically characterized, and an Hodgkin-Huxley computational model of DA PG cells has been elaborated (Pignatelli et al., 2005). The two conductances having the largest amplitude, responsible for the generation of the action potential, are a fast transient sodium current $(101 \mathrm{nS})$ and a delayed rectifier potassium current (50.1 nS; Pignatelli et al., 2005) - no other $\mathrm{K}^{+}$currents, as $\mathrm{I}_{\mathrm{A}}$, present in immature DA PG cells (see below) and in other mature PG cells subtypes (Fogli Iseppe et al., 2016) have been reported.

As most DA neurones, bulbar DA cells have a spontaneous activity, primarily within the theta frequency range $(4-12 \mathrm{~Hz})$; the pacemaking machinery is composed of a system of two small inward currents, a persistent sodium current $\left(\mathrm{I}_{\mathrm{Na}(\mathrm{P})} ; 0.41 \mathrm{nS}\right)$ and a T-type $\mathrm{Ca}^{2+}$ current $\left(\mathrm{I}_{\mathrm{Ca}(\mathrm{T})} ; 0.35 \mathrm{nS}\right.$; Pignatelli et al., 2012).

In addition to TTX, $\mathrm{I}_{\mathrm{Na}(\mathrm{P})}$ can be selectively blocked by riluzole (Urbani and Belluzzi, 2000), a drug used in the therapy of amyotrophic lateral sclerosis, and indeed riluzole $(5 \mu \mathrm{M})$ completely suppresses spontaneous firing.

The T-type calcium current is blocked by low concentrations of nickel (50-100 $\mu$ M; Lee et al., 1999), and by mibefradil (Mishra and Hermsmeyer, 1994), and both reversibly block spontaneous activity (Pignatelli et al., 2005).

Based on the kinetic data, a numerical reconstruction of the bulbar DA neurones according to the Hodgkin-Huxley model (Hodgkin and Huxley, 1952) has been developed (Pignatelli et al., 2005), which incorporates all the conductances detected and assuming the cell as a single electrotonically compact compartment. The in silico tests made possible by the model can be very helpful to uncover the essentials of the relative contribution of the currents sustaining the pacemaking process and their reciprocal interactions. The main outcomes obtained from the in silico cell model can be recapitulated as follows:

- the numerical cell model is capable to fire spontaneously at the same frequency of real neurones.

- the primum movens, the current which first sets in motion the process causing the progressive depolarization of the cell during the interspike interval, is the $\mathrm{I}_{\mathrm{Ca}(\mathrm{T})}$, replaced by $\mathrm{I}_{\mathrm{Na}(\mathrm{P})}$ in the second half of the slow depolarizing phase, until the threshold for the fast Na-current is reached and the action potential develops. Both currents are amazingly small in amplitude (max $4 \mathrm{pA}$ ) compared with sodium and delayed rectifier potassium currents underlying the action potential (about $1 \mathrm{nA}$ ) but, nevertheless, they are sufficient to depolarize DA PG cells, due to the high input resistance of these cells (about $700 \mathrm{M} \Omega$ ).

- in the numerical model-as in real preparations-both $\mathrm{I}_{\mathrm{Na}(\mathrm{P})}$ and $\mathrm{I}_{\mathrm{Ca}(\mathrm{T})}$ are required to sustain spontaneous activity, as the selective block of one or both of them abolishes the spontaneous firing: the in silico cell, as DA neurones, responds with a single spike to a depolarizing current pulse, but is unable to fire spontaneously when $\mathrm{I}_{\mathrm{Na}(\mathrm{P})}$ and $\mathrm{I}_{\mathrm{Ca}(\mathrm{T})}$ are zeroed.

the model indicates that the T-type calcium channels are decisive in determining the firing frequency as small changes in $\mathrm{I}_{\mathrm{Ca}(\mathrm{T})}$ conductance (from $0.35 \mathrm{nS}$ to $0.4 \mathrm{nS}$ ) suffice to change the spontaneous firing frequency from $8 \mathrm{~Hz}$ to $16 \mathrm{~Hz}$.

- the high voltage-activated calcium channels are not required for the pacemaking mechanism, and their blockage, both in living DA neurones and in the model, has no effect on the spontaneous firing frequency.

Two other small conductances, activated by hyperpolarization, are present in bulbar DA cells, not directly involved in the pacemaking machinery but playing an important role in its modulation: an h-current (Fried et al., 2010; Pignatelli et al., 2013) and a potassium inward rectifier (KIR) current (Borin et al., 2014). Both currents are active at rest, and exert opposite effects on the resting membrane potential, depolarizing the $\mathrm{h}$-current and hyperpolarizing the KIR, governing the resting membrane potential and consequently exerting an important role in controlling the excitability of these cells.

Both hyperpolarization-activated currents are effectively modulated by second messenger mechanisms, and DA neurones in the $\mathrm{OB}$ receive numerous afferents releasing a multiplicity of neurotransmitters, in many cases capable of affecting the cAMP pathway, and therefore potentially capable of modulating both $\mathrm{h}-$ and KIR currents. To name only a few, the $\mathrm{OB}$ receives serotoninergic afferents from the ventral and dorsal raphe nuclei (Araneda et al., 1980), noradrenergic input from the locus coeruleus (McLean et al., 1989), cholinergic inputs from the nucleus of the horizontal limb of the diagonal band (Zaborszky et al., 1986), and histaminergic inputs from hypothalamus (Panula et al., 1989). Accordingly, the KIR current is under the influence of a multiplicity of molecular pathways, which can either enhance the current, as it happens with $\mathrm{D} 2$, muscarinic, and $\mathrm{GABA}_{\mathrm{A}}$ receptor agonists, or have the contrary effect, as it is observed with $\alpha 1,5-\mathrm{HT}$ and histamine receptor agonists (Borin et al., 2014). Contrary to the KIR, the h-current seems to be modulated only by a single neurotransmitter, noradrenaline, which has a profound inhibitory influence on the current (Pignatelli et al., 2013). Taken together, these characteristics of the two currents activated by hyperpolarization provide the basis for a multiplicity of modulatory mechanisms converging onto DA-PG cells, making 
them fully qualified to reconfigure the bulbar network for better flexibility.

\section{ADULT NEUROGENESIS}

$\mathrm{OB}$ interneuron progenitors in mice generate from neural stem cells in the SVZ of the lateral ventricle (for recent reviews see Cave and Baker, 2015; Lledo and Valley, 2016; Malvaut and Saghatelyan, 2016). The adult SVZ can be subdivided into several domains identified by the expression of diverse transcription factors, highly conserved (Fujiwara and Cave, 2016). These domains produce neuroblasts committed to differentiate into distinct subsets of $\mathrm{OB}$ interneurones-DA progenitors are generated from the dorsolateral region (for a review see Fiorelli et al., 2015), characterized by the expression of the transcription factor Pax6 (Merkle et al., 2007; Young et al., 2007; Brill et al., 2008; Fernández et al., 2011). Pax6 is required for the development of the DAergic phenotype (Dellovade et al., 1998; Kohwi et al., 2005; Brill et al., 2008; Haba et al., 2009), and operates in association with the Dlx2 and Meis2 transcription factors (Brill et al., 2008; de Chevigny et al., 2012; Agoston et al., 2014). For its distinctive expression in terminally differentiated DAergic neurones and its requirement for their survival (Ninkovic et al., 2010), Pax6 can be considered almost a hallmark of bulbar DA neurones.

The rate of production of bulbar DA neurones is generally reported to increase in the postnatal/adult OB (Kosaka et al., 1987; McLean and Shipley, 1988; Winner et al., 2002; De Marchis et al., 2007, but see also Batista-Brito et al., 2008). Using in vivo imaging and genetic fate-mapping techniques, the fate of adult-born neurones has been traced over up to 9 months (Ninkovic et al., 2007; Adam and Mizrahi, 2011). The situation appear to be different in granule and glomerular layer: whereas in the granule cell layer after the second month the whole population of granules remain numerically stable, indicating that substantially there is only a turnover of this type of cells, in the glomerular layer the addition of new neurons to the adult bulbar network outnumbers by about $30 \%$ the cell loss in the glomerular layer (Ninkovic et al., 2007). Interestingly, this net addition does not concern all the adult-born cell of the GL, but only two subtypes, calretinin and DA interneurones (Ninkovic et al., 2007; Adam and Mizrahi, 2011), suggesting that the adult neurogenesis in the $\mathrm{OB}$ is subtype-specific, and regulated differently in granule and glomerular layer.

Several studies have shown that survival and integration of adult-born neurones in the OB critically depend on the fullness of the olfactory input, both processes being strongly enhanced by odor enrichment (Rochefort et al., 2002; Yamaguchi and Mori, 2005; Bonzano et al., 2014) - see also below. DA PG cells are the only bulbar interneurones receiving direct input from the olfactory nerve (Kosaka and Kosaka, 2007), and therefore it is not surprising that they are particularly sensitive to the level of olfactory input, which controls dynamically the turnover in a spatial and neuronal subtype-specific manner (Sawada et al., 2011).
As indicated above, in this context we will limit the discussion on the electrophysiological aspects of this process.

\section{ELECTROPHYSIOLOGY OF DA NEURONES DURING ADULT NEUROGENESIS}

Although mature DA neurones within the $\mathrm{OB}$ are expressed almost exclusively in the more external (glomerular) layer (Halász et al., 1981), spare neurones expressing the eGFP under the TH promoter have been observed also in the EPL, a neuropil-rich area positioned between the mitral and glomerular layers, and in a narrow region encompassing mitral and internal plexiform (M/IP) layers; these are cells in which the transcription of the TH gene occurs in the absence of significant translational activity (Baker et al., 2001; Jeong et al., 2003).

The presence of $\mathrm{TH}$ transcription in cells lying in a region devoid of DA neurones has been proposed to be ascribable to adult neurogenesis: the cells expressing TH but not DA could be newly generated neurones committed to a DA phenotype, just arrived in the M/IP following the rostral migratory stream (Saino-Saito et al., 2004), which could represent different stages of maturation of DA neurones. Since immature DA neurones have distinct physiological signatures, this hypothesis has been tested with targeted electrophysiological recordings at different levels within the OB (Pignatelli et al., 2009) using TH-GFP transgenic mice (Sawamoto et al., 2001); in immature DA neurones, the transcription of the TH gene is not immediately followed by translation (Baker et al., 2001), but in these neurones the eGFP gene, located under the same promoter, undergoes a certain degree of translation, small, but sufficient to allow these cells to become noticeably-although dimly-fluorescent.

TH-GFP neurones in the external plexiform and mitral/internal plexiform layers show very different excitability profiles. The TH-GFP cells of the EPL present the same set of voltage-dependent currents as for mature DA neurones of the glomerular layer, including fast transient and persistent Na-currents, T-type and L-type Ca-currents, and delayed rectifier potassium; accordingly, their behavior, irrespective of their position in the layer, is virtually identical to that of mature DA neurones in the glomerular layer, showing a spontaneous firing almost indistinguishable from that of the mature DA neurones of the GL (Pignatelli et al., 2009).

The mechanisms governing autorhythmicity of TH-GFP cells in external plexiform and glomerular layers are essentially the same: as for mature DA neurones, TH-GFP neurones in the EPL display a persistent Na-current $\left(\mathrm{I}_{\mathrm{NaP}}\right)$ and a T-type calcium current, and the pharmacological block of any of them also reversibly blocks the spontaneous activity (Pignatelli et al., 2012).

The appearance of the T-type calcium channel during maturation of TH-GFP cells has been studied by analyzing the expression of the calcium channel gene CAV3.2 in different groups of cells separated with fluorescent activated cell sorting (FACS) according to the intensity of their fluorescence (a value indicative of the maturation of the cell); the gene CAV3.2 has 
been selected for the sensitivity of the calcium channel encoded by this gene to low nickel (Lee et al., 1999). The results indicate a strong correlation (fivefold increase) between cell maturation and CAV3.2 mRNA levels, suggesting that the transcription of the gene coding for this channels is strongly associated with the process of maturation of DA neurones (Pignatelli et al., 2009).

Further information has been obtained from the analysis of $\left[\mathrm{Cl}^{-}\right]_{\mathrm{i}}$ in developing DA cells. Although it is the main inhibitory neurotransmitter in the mature brain, in the earlier phases of development GABA is excitatory, depolarizing the neurones by promoting an outflow of $\mathrm{Cl}^{-}$ions, as result of the unusual balance between the cation-chloride importer NKCC1 and the extruder KCC2; in newly generated cells this is dominated by the importer, leading to accumulation of $\mathrm{Cl}^{-}$inside the cell and to Nernstian equilibrium potential for $\mathrm{Cl}^{-}$ions positive with respect to the resting membrane potential (Ben-Ari et al., 2007). The analysis of $\left[\mathrm{Cl}^{-}\right]_{\mathrm{i}}$ in TH-GFP cells shows that this progressively decreases moving from M/IP to GL layers, and this observation is paralleled by an increase of the ratio extruder vs. accumulator in the same axis (Pignatelli et al., 2009).

The last observation concerning the maturation of DA neurones resulting from adult neurogenesis is about the establishment of synaptic connections with the existing network. Two well-established properties of mature DA neurones in the GL is that the large majority (about $80 \%$ ) of the afferent synapses are asymmetrical from olfactory nerve fibers (Toida et al., 2000) and that the full expression of the DAergic phenotype necessitates a well-structured input from olfactory receptor cells (Brunjes et al., 1985; Stone et al., 1991; Wilson and Wood, 1992; Baker et al., 1993; Cho et al., 1996).

The majority (75\%) of the TH-GFP cells in the EPL respond to ON stimulation with monosynaptic EPSP which can be reversibly suppressed by kynurenate (Pignatelli et al., 2009). On the contrary, the TH-GFP cells in the M/IP layer do not respond synaptically to the ON stimulation but are depolarized in response to focal application of glutamate, showing that they already have functional glutamate receptors (Pignatelli et al., 2009).

In this hypothesis, the faintly fluorescent cells observed in the mitral and internal plexiform layers could represent elements having arrested their migration process at this level, conceivably waiting for some consensus clue to come from the glomerular region allowing them to attain their final destination moving across the EPL while finalizing their differentiation towards the DAergic phenotype.

In a recent article, using a long-term in vivo single-cell tracking based on a newly developed optical cell positioning system, a series of remarkable new observations have been reported concerning the movements of neuroblasts once arrived in the OB (Liang et al., 2016). Of particular interest in this context, is the observation that some of the neuroblasts bound to the GL, "stopped for very long periods (from $12 \mathrm{~h}$ to a few days) before resuming the movement" (Liang et al., 2016), then crossed rapidly the EPL and once reached the GL switched to lateral movement, eventually integrating few glomeruli away from their entry point in the GL, and it is tempting to envisage that the cells showing this behavior could be DA neurones.

\section{EXPERIENCE-DEPENDENT PLASTICITY IN ADULT NEUROGENESIS}

A hallmark of bulbar DA neurones is their strong plasticity in response to sensory stimuli at multiple levels.

A first level of odor-driven plasticity observed in DA cells consists in their modulation by the olfactory input: sensory activity is fundamental for the development and maintenance of DA, but not of GABAergic, calretinin, or calbindin phenotypes, suggesting that DA neurones have a distinct reliance on odor-induced activity, marking a significant difference with respect to the other PG cells. DA neurone density is strongly and reversibly down-regulated in animals odor deprived following either chemical or surgical deafferentation of the OB (Nadi et al., 1981; Kawano and Margolis, 1982; Baker et al., 1983), or naris occlusion (Baker et al., 1983; Brunjes et al., 1985), an effect which applies to both pre-existing and adult-generated neurones (Bovetti et al., 2009; Bastien-Dionne et al., 2010). A drastic reduction of DA neurones ensues rapidly (4 days) the loss of sensory input (Baker et al., 1983), then proceeds more gradually, reaching a maximal $40 \%$ loss after 4 weeks (Sawada et al., 2011); although this phenomenon has long been known, the underlying molecular mechanisms are only beginning to emerge, and include transcriptional and epigenetic regulators (Banerjee et al., 2013; Bovetti et al., 2013) and microglia (Grier et al., 2016).

A second level of sensory-dependent plasticity of bulbar DA neurones involves environmental modulation of adult neurogenesis. In mice, an odor-enriched milieu has been shown to affect both adult neurogenesis and learning, an effect which is specific because it does not influence hippocampal neurogenesis (Rochefort et al., 2002), and it has been shown that this effect selectively affects the DA neurones, due to increased neurogenesis, whereas similar changes in calretinin or calbindin neurones were not observed (Bonzano et al., 2014), but see also (Kato et al., 2012). Odour enrichment or deprivation also increases or decreases, respectively, the survival of adult-born glomerular neurones, including DA cells (Bovetti et al., 2009), and odor deprivation upregulates the critical transcription factor Pax6 is in mice bulbar TH-positive cells (Bastien-Dionne et al., 2010).

A further level of sensory-dependent plasticity involves an activity-dependent upregulation of synaptogenesis of adult-born PG cells, also at the level of dendritic spines, and particularly prominent during their initial phases of development (Kelsch et al., 2009; Livneh et al., 2009); interestingly, plastic patterns of synaptic connectivity associated with learning has also been observed in adult-born granule cells (Breton-Provencher et al., 2016; Huang et al., 2016).

In this context, an interesting problem concerns the timing of DA neurogenesis and the functional inclusion of newborn neurones in the bulbar network. There is a general consensus 
on the principle that adult neurogenesis adds an essential degree of freedom to odor processing by adapting the $\mathrm{OB}$ circuitry to new olfactory signals or situations, but how could this be possible if it takes not less than 2 weeks to produce new neurones which are completely functionally integrated (Ortega-Perez et al., 2007)? In other words, how can the addition of new elements to the neuronal network be the response to an unexperienced functional context if the rewiring will only be realized well after the triggering stimulus is over? A similar objection was originally raised for neurogenesis in hippocampus (Kempermann, 2002).

The seminal observations on the phenotypic differentiation of DA progenitor cells in the OB put forward by the Harriett Baker group (Baker et al., 2001), suggest a different way to look at the problem: new cells are incessantly produced, complete their tangential migration to the $\mathrm{OB}$, and begin their differentiation process toward their final phenotype. They halt their radial migration halfway in the mitral cell layer, where they suspend their maturation process in a pre-terminal state, waiting for a consensus signal, which will allow them to perfect their differentiation towards the final phenotype and to take their place within the bulbar circuitry. What this consensus signal might be is not known, but the data from our group outlined above suggest that it follows the formation of a synaptic contact with the olfactory nerve. What we propose is that at any given moment there are new cells in the mitral cell layer committed to a DA phenotype but not fully mature sending their projection into the glomerular layer and trying to establish synaptic contacts. Failing to do so, the newly generated cell undergo apoptosis and die, what is actually known to be the fate of the majority of newborn cells reaching the OB (Biebl et al., 2000; Winner et al., 2002). If, on the contrary, an operative synaptic contact can be set up, possibly with a spine relocation process of the kind described in adult-born granule cells (Breton-Provencher et al., 2016), then the progenitor neurone completes its differentiation process migrating to its ultimate destination. Such a process might explain how the $\mathrm{OB}$ circuitry could rapidly adjust to better tackle new stimuli from the outside world, optimizing its wiring for a more effective signal processing. With a mechanism of this kind, the delay between a new sensory experience and the circuit modifications for optimal signal processing would be extremely small, as rewiring would only require the refinement and a short-range repositioning of plastic elements already present in situ, not a de novo production in a remote site.

\section{ROLE OF DA NEURONES IN THE OLFACTORY BULB}

At cellular level, the data of the literature about the role of DA neurones in the bulbar circuits are of uncertain interpretation. To limit the discussion to what has received ample experimental support, a role of DA in the $\mathrm{OB}$ is the inhibition of glutamate release in olfactory sensory fibers, via activation of $\mathrm{D}_{2}$ presynaptic receptors (Wachowiak and Cohen, 1999; Berkowicz and Trombley, 2000), activating an intracellular pathway suppressing of calcium influx through $\mathrm{N}$-type calcium channels (Wachowiak et al., 2005). The autorhythmicity of PG
DA neurones results in a tonic release of neurotransmitter in the synaptic cleft between DAergic cells from ON terminals, as shown by a $\sim 30 \%$ increase in levels of intracellular $\mathrm{Ca}^{2+}$ following the blockage of $\mathrm{D}_{2}$ receptors (Wachowiak and Cohen, 1999). DA can be eliminated from the synaptic cleft following a reuptake by the DA transporter (DAT) or by the breakdown enzyme catechol-O-methyl-transferase (COMT). A recent study of Cockerham et al. (2016) has examined the mechanisms of DA clearance in the synaptic space, showing that, contrary to what happens in the striatum, where the reuptake is mainly driven by the first, the predominant mechanism for DA clearance in the $\mathrm{OB}$ is the COMT breakdown. The authors suggest that the combined provisions of activity-dependent DA levels and activity independent COMT breakdown can extend the dynamic range of olfactory afferents in specific glomerular circuits (Cockerham et al., 2016) and/or could create adaptive odorant-specific filters for sensory inputs (McGann, 2013).

Larger DA neurones (a.k.a. SA cells), making interglomerular connections, establish synaptic contacts with ET cells, which in turn make direct excitatory synapses onto projection neurones (M/T cells). Using an optogenetic approach, the synapse between SA and ET cells has been characterized, showing that it elicits a biphasic response in ET cells with an initial $\mathrm{GABA}_{\mathrm{A}}$ receptormediated monosynaptic inhibition, followed by $D_{1}$ receptormediated excitation (Liu et al., 2013). The integration of the two responses is made by the h-current: an initial $\mathrm{GABA}_{\mathrm{A}}$ receptor-mediated a hyperpolarization, activating an h-current, is immediately followed by the action of the co-released DA, which potentiates the $\mathrm{I}_{\mathrm{h}}$, with a consequent depolarizing rebound of the membrane potential (Liu et al., 2013). The net result of the biphasic response observed in ET cells is that it could act as a gate in the transmission of sensory signals to projecting neurones (Banerjee et al., 2015), influencing the processing of sensory input with a mechanism that could be further tuned by the regulation of GABA vs. DA action by COMT (Cockerham et al., 2016).

At a functional level, the contribution of mature and/or newborn DA neurones in odor processing remains substantially elusive, although a certain number of considerations can be made, derived from direct experimental investigation or by analogy with other DA systems.

To begin with, it is not clear the contribution of DA neurones in odor detection, as mice knockout for D2 receptors have an almost normal capability to detect or discriminate odors; however, their ability to elaborate a correct response to unpredicted odor-driven contingencies or situations is significantly impaired (Kruzich and Grandy, 2004). In behavioral terms, this could be described a severe impairment in reversal learning, a measure of cognitive flexibility (Izquierdo et al., 2016), and therefore a kind of processing which is likely to take place in circuits higher than the OB.

More focused on the role of DA cells in bulbar circuitry is a recent study, confirming an earlier observation (Davila et al., 2003), which demonstrates that DA cells, via ET cells-to which they are coupled with chemical and electrical synapses-inhibit mitral and tufted cells, thereby controlling the gain and 
decreasing the correlation of odor images in projection neurones (Banerjee et al., 2015).

In accordance with the key function attributable to DA cells for their strategic position at the entry of the bulbar circuitry, several studies have suggested a major role of the DA system in specific aspects of odor processing and of odor-driven behaviors, to cite only a couple odor discrimination and reproduction.

As already outlined above, the DAergic system is involved in odor discrimination rather than in odor detection (Kruzich and Grandy, 2004). Increasing of DA levels by injecting the dopamine precursor L-DOPA in rats improves olfactory discrimination capabilities in forced choice odor discrimination task (Pavlis et al., 2006), and mice lacking the DAT show discrimination deficits (Tillerson et al., 2006). The mechanism is mediated by modulation of $\mathrm{D} 2$ receptors and affects discrimination capabilities by altering the perceived odor intensity (Doty and Risser, 1989; Wei et al., 2006).

Reproduction sees an important participation of the DAergic system in different moments, from mating to offspring recognition. Aftermating odor perception is associated with a surge of TH expression in PGCs and DA transmission in the OB (Serguera et al., 2008). This rise in DA release translates into inhibition of $\mathrm{ON}$ terminals and downturn of sensory input and excitation of the $\mathrm{OB}$ projection neurones, eventually blocking social olfactory cues detrimental to pregnancy (Serguera et al., 2008). DA levels increase significantly in the OB during parturition and suckling (Kendrick et al., 1988), deeply influencing the maternal behavior (Keverne et al., 1993).

\section{CONCLUDING REMARKS}

Although bulbar DA cells have been the object of many studies covering their histological and electrophysiological profiles, it is amazing that the functional role of what is the largest population of DAergic neurones in the brain remains in the shadow under many aspects, and this is particularly true for adult-born DA

\section{REFERENCES}

Adam, Y., and Mizrahi, A. (2011). Long-term imaging reveals dynamic changes in the neuronal composition of the glomerular layer. J. Neurosci. 31, 7967-7973. doi: 10.1523/JNEUROSCI.0782-11.2011

Agoston, Z., Heine, P., Brill, M. S., Grebbin, B. M., Hau, A. C., KallenbornGerhardt, W., et al. (2014). Meis2 is a Pax6 co-factor in neurogenesis and dopaminergic periglomerular fate specification in the adult olfactory bulb. Development 141, 28-38. doi: 10.1242/dev.097295

Altman, J. (1969). Autoradiographic and histological studies of postnatal neurogenesis. IV. Cell proliferationand migration in the anterior forebrain, with special reference to persisting neurogenesis in the olfactory bulb. J. Comp. Neurol. 137, 433-457. doi: 10.1002/cne.901370404

Araneda, S., Gamrani, H., Font, C., Calas, A., Pujol, J. F., and Bobillier, P. (1980). Retrograde axonal transport following injection of [3H]-serotonin into the olfactory bulb. II. Radioautographic study. Brain Res. 196, 417-427. doi: 10.1016/0006-8993(80)90405-9

Baker, H., Kawano, T., Margolis, F. L., and Joh, T. H. (1983). Transneuronal regulation of tyrosine hydroxylase expression in olfactory bulb of mouse and rat. J. Neurosci. 3, 69-78.

Baker, H., Liu, N., Chun, H. S., Saino, S., Berlin, R., Volpe, B., et al. (2001). Phenotypic differentiation during migration of cells. Understanding how DA neurones contribute to signal processing in the bulbar network requires a finer knowledge of their connections, not as much under the anatomical aspect as under the dynamic aspect, and of their "molecular" (Bhalla, 2014) computational capabilities. New technical approaches are progressively revealing new levels of complexity in the computational capabilities of these cells, and in the variety of the roles they can play, and we can expect interesting developments in the incoming years.

Adult neurogenesis of DA neurones also in humans (Inta et al., 2015), demonstrating the capacity of the mature CNS to regenerate cells whose loss is responsible for devastating neurodegenerative diseases, has turned on hopes that understanding the mechanisms governing adult neurogenesis could promote new strategies for cell replacement therapies, either by implementing the endogenous neurogenic potential or by transplants of highly neurogenic stem cell supplies. To date, despite the considerable amount of information accumulated on adult neurogenesis in the course of the last 20 years, no significant translational improvements have been achieved for most neurological diseases, including those more directly linked to a damage of the DA system, and the translational gap remains wide open (Cattaneo and Bonfanti, 2014), but a reasonable possibility that filling this gap is not just a hope do exist; the years to come might substantiate this expectation, and the DAergic neurones of the $\mathrm{OB}$ might be a main character in the play.

\section{AUTHOR CONTRIBUTIONS}

OB: MS drafting; AP: bibliographic research.

\section{FUNDING}

This work was funded by the University of Ferrara, FAR 2015 program to $\mathrm{OB}$.

dopaminergic progenitor cells to the olfactory bulb. J. Neurosci. 21, 8505-8513.

Baker, H., Morel, K., Stone, D. M., and Maruniak, J. A. (1993). Adult naris closure profoundly reduces tyrosine hydroxylase expression in mouse olfactory bulb. Brain Res. 614, 109-116. doi: 10.1016/0006-8993(93)91023-1

Banerjee, K., Akiba, Y., Baker, H., and Cave, J. W. (2013). Epigenetic control of neurotransmitter expression in olfactory bulb interneurons. Int. J. Dev. Neurosci. 31, 415-423. doi: 10.1016/j.ijdevneu.2012.11.009

Banerjee, A., Marbach, F., Anselmi, F., Koh, M. S., Davis, M. B., Garcia da, S. P., et al. (2015). An interglomerular circuit gates glomerular output and implements gain control in the mouse olfactory bulb. Neuron 87, 193-207. doi: 10.1016/j.neuron.2015.06.019

Bastien-Dionne, P. O., David, L. S., Parent, A., and Saghatelyan, A. (2010). Role of sensory activity on chemospecific populations of interneurons in the adult olfactory bulb. J. Comp. Neurol. 518, 1847-1861. doi: 10.1002/cne. 22307

Batista-Brito, R., Close, J., Machold, R., and Fishell, G. (2008). The distinct temporal origins of olfactory bulb interneuron subtypes. J. Neurosci. 28, 3966-3975. doi: 10.1523/JNEUROSCI.5625-07.2008

Ben-Ari, Y., Gaiarsa, J. L., Tyzio, R., and Khazipov, R. (2007). GABA: a pioneer transmitter that excites immature neurons and generates primitive oscillations. Physiol. Rev. 87, 1215-1284. doi: 10.1152/physrev.00017.2006 
Berkowicz, D. A., and Trombley, P. Q. (2000). Dopaminergic modulation at the olfactory nerve synapse. Brain Res. 855, 90-99. doi: 10.1016/s00068993(99)02342-2

Betarbet, R., Zigova, T., Bakay, R. A., and Luskin, M. B. (1996). Dopaminergic and GABAergic interneurons of the olfactory bulb are derived from the neonatal subventricular zone. Int. J. Dev. Neurosci. 14, 921-930. doi: 10.1016/s07365748(96)00066-4

Bhalla, U. S. (2014). Molecular computation in neurons: a modeling perspective. Curr. Opin. Neurobiol. 25, 31-37. doi: 10.1016/j.conb.2013.11.006

Biebl, M., Cooper, C. M., Winkler, J., and Kuhn, H. G. (2000). Analysis of neurogenesis and programmed cell death reveals a self-renewing capacity in the adult rat brain. Neurosci. Lett. 291, 17-20. doi: 10.1016/s0304-3940(00)01368-9

Björklund, A., and Dunnett, S. B. (2007). Dopamine neuron systems in the brain: an update. Trends Neurosci. 30, 194-202. doi: 10.1016/j.tins.2007.03.006

Bonzano, S., Bovetti, S., Fasolo, A., Peretto, P., and De Marchis, S. (2014). Odour enrichment increases adult-born dopaminergic neurons in the mouse olfactory bulb. Eur. J. Neurosci. 40, 3450-3457. doi: 10.1111/ejn.12724

Bonzano, S., Bovetti, S., Gendusa, C., Peretto, P., and De Marchis, S. (2016). Adult born olfactory bulb dopaminergic interneurons: molecular determinants and experience-dependent plasticity. Front. Neurosci. 10:189. doi: 10.3389/fnins. 2016.00189

Borin, M., Fogli Iseppe, A., Pignatelli, A., and Belluzzi, O. (2014). Inward rectifier potassium $\left(\mathrm{K}_{\mathrm{ir}}\right)$ current in dopaminergic periglomerular neurons of the mouse olfactory bulb. Front. Cell. Neurosci. 8:223. doi: 10.3389/fncel.2014.00223

Borisovska, M., Bensen, A. L., Chong, G., and Westbrook, G. L. (2013). Distinct modes of dopamine and GABA release in a dual transmitter neuron. J. Neurosci. 33, 1790-1796. doi: 10.1523/JNEUROSCI.4342-12.2013

Bovetti, S., Bonzano, S., Garzotto, D., Giannelli, S. G., Iannielli, A., Armentano, M., et al. (2013). COUP-TFI controls activity-dependent tyrosine hydroxylase expression in adult dopaminergic olfactory bulb interneurons. Development 140, 4850-4859. doi: 10.1242/dev.089961

Bovetti, S., Veyrac, A., Peretto, P., Fasolo, A., and De Marchis, S. (2009). Olfactory enrichment influences adult neurogenesis modulating GAD67 and plasticityrelated molecules expression in newborn cells of the olfactory bulb. PLoS One 4:e6359. doi: 10.1371/journal.pone.0006359

Breton-Provencher, V., Bakhshetyan, K., Hardy, D., Bammann, R. R., Cavarretta, F., Snapyan, M., et al. (2016). Principal cell activity induces spine relocation of adult-born interneurons in the olfactory bulb. Nat. Commun. 7:12659. doi: 10.1038/ncomms12659

Brill, M. S., Snapyan, M., Wohlfrom, H., Ninkovic, J., Jawerka, M., Mastick, G. S., et al. (2008). A dlx2- and pax6-dependent transcriptional code for periglomerular neuron specification in the adult olfactory bulb. J. Neurosci. 28, 6439-6452. doi: 10.1523/JNEUROSCI.0700-08.2008

Brunjes, P. C., Smith-Crafts, L. K., and McCarty, R. (1985). Unilateral odor deprivation: effects on the development of olfactory bulb catecholamines and behavior. Brain Res. 354, 1-6. doi: 10.1016/0165-3806(85)90063-x

Caiazzo, M., Colucci-D’Amato, L., Volpicelli, F., Speranza, L., Petrone, C., Pastore, L., et al. (2011). Krüppel-like factor 7 is required for olfactory bulb dopaminergic neuron development. Exp. Cell Res. 317, 464-473. doi: 10.1016/j. yexcr.2010.11.006

Cattaneo, E., and Bonfanti, L. (2014). Therapeutic potential of neural stem cells: greater in people's perception than in their brains? Front. Neurosci. 8:79. doi: 10.3389/fnins.2014.00079

Cave, J. W., Akiba, Y., Banerjee, K., Bhosle, S., Berlin, R., and Baker, H. (2010). Differential regulation of dopaminergic gene expression by Er81. J. Neurosci. 30, 4717-4724. doi: 10.1523/JNEUROSCI.0419-10.2010

Cave, J. W., and Baker, H. (2009). Dopamine systems in the forebrain. Adv. Exp. Med. Biol. 651, 15-35. doi: 10.1007/978-1-4419-0322-8_2

Cave, J. W., and Baker, H. (2015). "Adult neurogenesis in the subventricular zone and migration to the olfactory bulb," in Handbook of Olfaction and Gustation, ed. R. L. Doty (Hoboken, NJ: John Wiley and Sons Inc), 183-207.

Cave, J. W., Wang, M., and Baker, H. (2014). Adult subventricular zone neural stem cells as a potential source of dopaminergic replacement neurons. Front. Neurosci. 8:16. doi: 10.3389/fnins.2014.00016

Chand, A. N., Galliano, E., Chesters, R. A., and Grubb, M. S. (2015). A distinct subtype of dopaminergic interneuron displays inverted structural plasticity at the axon initial segment. J. Neurosci. 35, 1573-1590. doi: 10.1523/JNEUROSCI. 3515-14.2015
Cho, J. Y., Min, N., Franzen, L., and Baker, H. (1996). Rapid down-regulation of tyrosine hydroxylase expression in the olfactory bulb of naris-occluded adult rats. J. Comp. Neurol. 369, 264-276. doi: 10.1002/(sici)10969861(19960527)369:2<264::aid-cne7 > 3.3.co;2-1

Cockerham, R., Liu, S., Cachope, R., Kiyokage, E., Cheer, J. F., Shipley, M. T., et al. (2016). Subsecond regulation of synaptically released dopamine by COMT in the olfactory bulb. J. Neurosci. 36, 7779-7785. doi: 10.1523/JNEUROSCI.065816.2016

Dahlström, A., and Fuxe, K. (1964). Evidence for the existence of monoaminecontaining neurons in the central nervous system. I. Demonstration of monoamines in the cell bodies of brain stem neurones. Acta Physiol. Scand. Suppl. 232, 1-55.

Davila, N. G., Blakemore, L. J., and Trombley, P. Q. (2003). Dopamine modulates synaptic transmission between rat olfactory bulb neurons in culture. J. Neurophysiol. 90, 395-404. doi: 10.1152/jn.01058.2002

Davis, B. J., and Macrides, F. (1983). Tyrosine hydroxylase immunoreactive neurons and fibers in the olfactory system of hamster. J. Comp. Neurol. 214, 427-440. doi: 10.1002/cne.902140407

de Chevigny, A., Core, N., Follert, P., Wild, S., Bosio, A., yoshikawa, K., et al. (2012). Dynamic expression of the pro-dopaminergic transcription factors Pax6 and Dlx2 during postnatal olfactory bulb neurogenesis. Front. Cell. Neurosci. 6:6. doi: 10.3389/fncel.2012.00006

De Marchis, S., Bovetti, S., Carletti, B., Hsieh, Y. C., Garzotto, D., Peretto, P., et al. (2007). Generation of distinct types of periglomerular olfactory bulb interneurons during development and in adult mice: implication for intrinsic properties of the subventricular zone progenitor population. J. Neurosci. 27, 657-664. doi: 10.1523/JNEUROSCI.2870-06.2007

Dellovade, T. L., Pfaff, D. W., and Schwanzel-Fukuda, M. (1998). Olfactory bulb development is altered in small-eye (Sey) mice. J. Comp. Neurol. 402, 402-418. doi: 10.1002/(SICI)1096-9861(19981221)402:3 < 402::AID-CNE8 > 3.3.CO;2-S

Doty, R. L. (2012). Olfactory dysfunction in Parkinson disease. Nat. Rev. Neurol. 8, 329-339. doi: 10.1038/nrneurol.2012.80

Doty, R. L., and Risser, J. M. (1989). Influence of the D-2 dopamine receptor agonist quinpirole on the odor detection performance of rats before and after spiperone administration. Psychopharmacology (Berl) 98, 310-315. doi: $10.1007 / \mathrm{bf} 00451680$

Dubach, M. (1994). "Telencephalic dopamine cells in monkeys, humans and rats," in Phylogeny and Development of Catecholamine Systems in the CNS of Vertebrates, ed. W. J. A. J. Smeets and A. Reiner, (Cambridge, CA: Cambridge University Press), 273-287.

Felten, D. L., Sladek, J. R. Jr. (1983). Monoamine distribution in primate brain V. Monoaminergic nuclei: anatomy, pathways and local organization. Brain Res. Bull. 10, 171-284. doi: 10.1016/0361-9230(83)90045-x

Fernández, M. E., Croce, S., Boutin, C., Cremer, H., and Raineteau, O. (2011). Targeted electroporation of defined lateral ventricular walls: a novel and rapid method to study fate specification during postnatal forebrain neurogenesis. Neural Dev. 6:13. doi: 10.1186/1749-8104-6-13

Fiorelli, R., Azim, K., Fischer, B., and Raineteau, O. (2015). Adding a spatial dimension to postnatal ventricular-subventricular zone neurogenesis. Development 142, 2109-2120. doi: 10.1242/dev.119966

Fogli Iseppe, A., Pignatelli, A., and Belluzzi, O. (2016). Calretinin-periglomerular interneurons in mice olfactory bulb: cells of few words. Front. Cell. Neurosci. 10:231. doi: 10.3389/fncel.2016.00231

Flames, N., and Hobert, O. (2009). Gene regulatory logic of dopamine neuron differentiation. Nature 458, 885-889. doi: 10.1038/nature07929

Fried, H. U., Kaupp, U. B., and Müller, F. (2010). Hyperpolarizationactivated and cyclic nucleotide-gated channels are differentially expressed in juxtaglomerular cells in the olfactory bulb of mice. Cell Tissue Res. 339, 463-479. doi: 10.1007/s00441-009-0904-9

Fujiwara, N., and Cave, J. W. (2016). Partial conservation between mice and humans in olfactory bulb interneuron transcription Factor Codes. Front. Neurosci. 10:337. doi: 10.3389/fnins.2016.00337

Gall, C. M., Hendry, S. H., Seroogy, K. B., Jones, E. G., and Haycock, J. W. (1987). Evidence for coexistence of GABA and dopamine in neurons of the rat olfactory bulb. J. Comp. Neurol. 266, 307-318. doi: 10.1002/cne.902660302

Galliano, E., and Grubb, M. (2016). "Not all dopaminergic neurones are created equal," in Proceedings of the 10th Federation of European Neuroscience Societies Meeting Copenhagen, (Denmark). 
Grier, B. D., Belluscio, L., and Cheetham, C. E. J. (2016). Olfactory sensory activity modulates microglial-neuronal interactions during dopaminergic cell loss in the olfactory bulb. Front. Cell. Neurosci. 10:178. doi: 10.3389/fncel.2016.00178

Guyenet, P. G., and Crane, J. K. (1981). Non-dopaminergic nigrostriatal pathway. Brain Res. 213, 291-305. doi: 10.1016/0006-8993(81)90235-3

Haba, H., Nomura, T., Suto, F., and Osumi, N. (2009). Subtype-specific reduction of olfactory bulb interneurons in Pax6 heterozygous mutant mice. Neurosci. Res. 65, 116-121. doi: 10.1016/j.neures.2009.05.011

Hack, M. A., Saghatelyan, A., de Chevigny, A., Pfeifer, A., Ashery-Padan, R., Lledo, P. M., et al. (2005). Neuronal fate determinants of adult olfactory bulb neurogenesis. Nat. Neurosci. 8, 865-872. doi: 10.1038/nn1479

Halász, N. (1990). The Vertebrate Olfactory System: Chemical Neuroanatomy, Function and Development. Budapest: Académiai Kiadó.

Halász, N., Johansson, O., Hökfelt, T., Ljungdahl, A., and Goldstein, M. (1981). Immunohistochemical identification of two types of dopamine neuron in the rat olfactory bulb as seen by serial sectioning. J. Neurocytol. 10, 251-259. doi: $10.1007 / \mathrm{bf} 01257970$

Havrda, M. C., Harris, B. T., Mantani, A., Ward, N. M., Paolella, B. R., Cuzon, V. C., et al. (2008). Id2 is required for specification of dopaminergic neurons during adult olfactory neurogenesis. J. Neurosci. 28, 14074-14087. doi: 10.1523/jneurosci.3188-08.2008

Hodgkin, A. L., and Huxley, A. F. (1952). A quantitative description of membrane currents and its application to conduction and excitation in nerve. J. Physiol. 117, 500-544. doi: 10.1113/jphysiol.1952.sp004764

Hökfelt, T., Martensson, R., Björklund, A., Kheinau, S., and Goldstein, M. (1984). "Distributional maps of tyrosine-hydroxylase-immunoreactive neurons in the rat brain," in Handbook of Chemical Neuroanatomy. (Classical Transmitters in the CNS, Part I), eds A. Björklund and T. Hökfelt (Amsterdam: Elsevier), 277-379.

Hoogland, P. V., and Huisman, E. (1999). Tyrosine hydroxylase immunoreactive structures in the aged human olfactory bulb and olfactory peduncle. J. Chem. Neuroanat. 17, 153-161. doi: 10.1016/s0891-0618(99)00035-6

Huang, L., Ung, K., Garcia, I., Quast, K. B., Cordiner, K., Saggau, P., et al. (2016). Task learning promotes plasticity of interneuron connectivity maps in the olfactory bulb. J. Neurosci. 36, 8856-8871. doi: 10.1523/JNEUROSCI.0794-16. 2016

Imai, T. (2014). Construction of functional neuronal circuitry in the olfactory bulb. Semin. Cell Dev. Biol. 35, 180-188. doi: 10.1016/j.semcdb.2014. 07.012

Inta, D., Cameron, H. A., and Gass, P. (2015). New neurons in the adult striatum: from rodents to humans. Trends Neurosci. 38, 517-523. doi: 10.1016/j.tins. 2015.07.005

Izquierdo, A., Brigman, J. L., Radke, A. K., Rudebeck, P. H., and Holmes, A. (2016). The neural basis of reversal learning: an updated perspective. Neuroscience doi: 10.1016/j.neuroscience.2016.03.021 [Epub ahead of print].

Jeong, Y. G., Lee, N. S., Lee, K. Y., Chung, S. H., Hwang, I. K., Suh, J. G., et al. (2003). Morphological characteristics of dopaminergic immunoreactive neurons in the olfactory bulb of the common marmoset monkey (Callithrix jacchus). Ann. Anat. 185, 543-547. doi: 10.1016/s0940-9602(03) 80123-1

Kato, Y., Kaneko, N., Sawada, M., Ito, K., Arakawa, S., Murakami, S., et al. (2012). A subtype-specific critical period for neurogenesis in the postnatal development of mouse olfactory glomeruli. PLoS One 7:e48431. doi: 10.1371/journal.pone.0048431

Kawano, T., and Margolis, F. L. (1982). Transsynaptic regulation of olfactory bulb catecholamines in mice and rats. J. Neurochem. 39, 342-348. doi: 10.1111/j. 1471-4159.1982.tb03953.x

Kelsch, W., Lin, C. W., Mosley, C. P., and Lois, C. (2009). A critical period for activity-dependent synaptic development during olfactory bulb adult neurogenesis. J. Neurosci. 29, 11852-11858. doi: 10.1523/JNEUROSCI.2406-09. 2009

Kempermann, G. (2002). Why new neurons? Possible functions for adult hippocampal neurogenesis. J. Neurosci. 22, 635-638.

Kendrick, K. M., Keverne, E. B., Chapman, C., and Baldwin, B. A. (1988). Intracranial dialysis measurement of oxytocin, monoamine and uric acid release from the olfactory bulb and substantia nigra of sheep during parturition, suckling, separation from lambs and eating. Brain Res. 439, 1-10. doi: 10.1016/0006-8993(88)91455-2
Keverne, E. B., Lévy, F., Guevara-Guzman, R., and Kendrick, K. M. (1993). Influence of birth and maternal experience on olfactory bulb neurotransmitter release. Neuroscience 56, 557-565. doi: 10.1016/0306-4522(93)90356-k

Kiyokage, E., Pan, Y. Z., Shao, Z., Kobayashi, K., Szabo, G., Yanagawa, Y., et al. (2010). Molecular identity of periglomerular and short axon cells. J. Neurosci. 30, 1185-1196. doi: 10.1523/JNEUROSCI.3497-09.2010

Kohwi, M., Osumi, N., Rubenstein, J. L., and Alvarez-Buylla, A. (2005). Pax6 is required for making specific subpopulations of granule and periglomerular neurons in the olfactory bulb. J. Neurosci. 25, 6997-7003. doi: 10.1523/jneurosci.1435-05.2005

Kosaka, K., Hama, K., Nagatsu, I., Wu, J. Y., Ottersen, O. P., StormMathisen, J., et al. (1987). Postnatal development of neurons containing both catecholaminergic and GABAergic traits in the rat main olfactory bulb. Brain Res. 403, 355-360. doi: 10.1016/0006-8993(87)90075-8

Kosaka, K., and Kosaka, T. (2007). Chemical properties of type 1 and type 2 periglomerular cells in the mouse olfactory bulb are different from those in the rat olfactory bulb. Brain Res. 1167, 42-55. doi: 10.1016/j.brainres.2007. 04.087

Kosaka, T., Hataguchi, Y., Hama, K., Nagatsu, I., and Wu, J. Y. (1985). Coexistence of immunoreactivities for glutamate decarboxylase and tyrosine hydroxylase in some neurons in the periglomerular region of the rat main olfactory bulb: possible coexistence of $\beta$-aminobutyric acid (GABA) and dopamine. Brain Res. 343, 166-171. doi: 10.1016/0006-8993(85)91172-2

Kosaka, T., and Kosaka, K. (2008). Tyrosine hydroxylase-positive GABAergic juxtaglomerular neurons are the main source of the interglomerular connections in the mouse main olfactory bulb. Neurosci. Res. 60, 349-354. doi: 10.1016/j.neures.2007.11.012

Kosaka, T., and Kosaka, K. (2009). Two types of tyrosine hydroxylase positive GABAergic juxtaglomerular neurons in the mouse main olfactory bulb are different in their time of origin. Neurosci. Res. 64, 436-441. doi: 10.1016/j. neures.2009.04.018

Kosaka, T., and Kosaka, K. (2011). "Interneurons" in the olfactory bulb revisited. Neurosci. Res. 69, 93-99. doi: 10.1016/j.neures.2010.10.002

Kosaka, T., and Kosaka, K. (2016). Neuronal organization of the main olfactory bulb revisited. Anat. Sci. Int. 91, 115-127. doi: 10.1007/s12565-015-0309-7

Kratskin, I., and Belluzzi, O. (2003). "Anatomy and neurochemistry of the olfactory bulb," in Handbook of Olfaction and Gustation, ed. R. L. Doty (New York, NY: Marcel Dekker), 139-164.

Kruzich, P. J., and Grandy, D. K. (2004). Dopamine D2 receptors mediate two-odor discrimination and reversal learning in $\mathrm{C} 57 \mathrm{BL} / 6$ mice. $B M C$ Neurosci. 5:12. doi: 10.1186/1471-2202-5-12

Lazarini, F., Gabellec, M. M., Moigneu, C., de Chaumont, F., OlivoMarin, J. C., and Lledo, P. M. (2014). Adult neurogenesis restores dopaminergic neuronal loss in the olfactory bulb. J. Neurosci. 34, 14430-14442. doi: 10.1523/JNEUROSCI.5366-13.2014

Lee, J. H., Gomora, J. C., Cribbs, L. L., and Perez-Reyes, E. (1999). Nickel block of three cloned T-type calcium channels: low concentrations selectively block $\alpha$ 1H. Biophys. J. 77, 3034-3042. doi: 10.1016/s0006-3495(99)77134-1

Liang, Y., Li, K., Riecken, K., Maslyukov, A., Gomez-Nicola, D., Kovalchuk, Y., et al. (2016). Long-term in vivo single-cell tracking reveals the switch of migration patterns in adult-born juxtaglomerular cells of the mouse olfactory bulb. Cell Res. 26, 805-821. doi: 10.1038/cr.2016.55

Liberia, T., Blasco-Ibáñez, J. M., Nácher, J., Varea, E., Zwafink, V., and Crespo, C. (2012). Characterization of a population of tyrosine hydroxylase-containing interneurons in the external plexiform layer of the rat olfactory bulb. Neuroscience 217, 140-153. doi: 10.1016/j.neuroscience.2012.05.007

Liu, S., Plachez, C., Shao, Z., Puche, A., and Shipley, M. T. (2013). Olfactory bulb short axon cell release of GABA and dopamine produces a temporally biphasic inhibition-excitation response in external tufted cells. J. Neurosci. 33, 2916-2926. doi: 10.1523/JNEUROSCI.3607-12.2013

Livneh, Y., Feinstein, N., Klein, M., and Mizrahi, A. (2009). Sensory input enhances synaptogenesis of adult-born neurons. J. Neurosci. 29, 86-97. doi: 10.1523/JNEUROSCI.4105-08.2009

Lledo, P. M., and Valley, M. (2016). Adult olfactory bulb neurogenesis. Cold Spring Harb. Perspect. Biol. 8:a018945. doi: 10.1101/cshperspect.a018945

Lodovichi, C., Belluscio, L., and Katz, L. C. (2003). Functional topography of connections linking mirror-symmetric maps in the mouse olfactory bulb. Neuron 38, 265-276. doi: 10.1016/s0896-6273(03)00194-6 
Maher, B. J., and Westbrook, G. L. (2008). Co-transmission of dopamine and GABA in periglomerular cells. J. Neurophysiol. 99, 1559-1564. doi: 10.1152/jn. 00636.2007

Malvaut, S., and Saghatelyan, A. (2016). The role of adult-born neurons in the constantly changing olfactory bulb network. Neural Plast. 2016:1614329. doi: 10.1155/2016/1614329

Marei, H. E., and Ahmed, A. E. (2013). Transcription factors expressed in embryonic and adult olfactory bulb neural stem cells reveal distinct proliferation, differentiation and epigenetic control. Genomics 101, 12-19. doi: 10.1016/j.ygeno.2012.09.006

McGann, J. P. (2013). Presynaptic inhibition of olfactory sensory neurons: new mechanisms and potential functions. Chem. Senses 38, 459-474. doi: 10.1093/chemse/bjt018

McLean, J. H., and Shipley, M. T. (1988). Postmitotic, postmigrational expression of tyrosine hydroxylase in olfactory bulb dopaminergic neurons. J. Neurosci. 8, 3658-3669.

McLean, J. H., Shipley, M. T., Nickell, W. T., Aston-Jones, G., and Reyher, C. K. (1989). Chemoanatomical organization of the noradrenergic input from locus coeruleus to the olfactory bulb of the adult rat. J. Comp. Neurol. 285, 339-349. doi: 10.1002/cne.902850305

Merkle, F. T., Mirzadeh, Z., and Alvarez-Buylla, A. (2007). Mosaic organization of neural stem cells in the adult brain. Science 317, 381-384. doi: 10.1126/science. 1144914

Mishra, S. K., and Hermsmeyer, K. (1994). Selective inhibition of T-type $\mathrm{Ca}^{2+}$ channels by Ro 40-5967. Circ. Res. 75, 144-148. doi: 10.1161/01.res. 75.1 .144

Mizrahi, A., Lu, J., Irving, R., Feng, G., and Katz, L. C. (2006). In vivo imaging of juxtaglomerular neuron turnover in the mouse olfactory bulb. Proc. Natl. Acad. Sci. U S A 103, 1912-1917. doi: 10.1073/pnas.05062 97103

Nadi, N. S., Head, R., Grillo, M., Hempstead, J., Grannot-Reisfeld, N., and Margolis, F. L. (1981). Chemical deafferentation of the olfactory bulb: plasticity of the levels of tyrosine hydroxylase, dopamine and norepinephrine. Brain Res. 213, 365-377. doi: 10.1016/0006-8993(81)90241-9

Nagayama, S., Homma, R., and Imamura, F. (2014). Neuronal organization of olfactory bulb circuits. Front. Neural Circuits 8:98. doi: 10.3389/fncir.2014. 00098

Ninkovic, J., Mori, T., and Gotz, M. (2007). Distinct modes of neuron addition in adult mouse neurogenesis. J. Neurosci. 27, 10906-10911. doi: 10.1523/JNEUROSCI.2572-07.2007

Ninkovic, J., Pinto, L., Petricca, S., Lepier, A., Sun, J., Rieger, M. A., et al. (2010). The transcription factor Pax6 regulates survival of dopaminergic olfactory bulb neurons via crystallin $\alpha$ A. Neuron 68, 682-694. doi: 10.1016/j.neuron.2010. 09.030

Ortega-Perez, I., Murray, K., and Lledo, P. M. (2007). The how and why of adult neurogenesis. J. Mol. Histol. 38, 555-562. doi: 10.1007/s10735-007-9114-5

Panula, P., Pirvola, U., Auvinen, S., and Airaksinen, M. S. (1989). Histamineimmunoreactive nerve fibers in the rat brain. Neuroscience 28, 585-610. doi: 10.1016/0306-4522(89)90007-9

Panzanelli, P., Fritschy, J. M., Yanagawa, Y., Obata, K., and Sassoè-Pognetto, M. (2007). GABAergic phenotype of periglomerular cells in the rodent olfactory bulb. J. Comp. Neurol. 502, 990-1002. doi: 10.1002/cne.21356

Parrish-Aungst, S., Shipley, M. T., Erdelyi, F., Szabo, G., and Puche, A. C. (2007). Quantitative analysis of neuronal diversity in the mouse olfactory bulb. J. Comp. Neurol. 501, 825-836. doi: 10.1002/cne.21205

Pavlis, M., Feretti, C., Levy, A., Gupta, N., and Linster, C. (2006). 1-DOPA improves odor discrimination learning in rats. Physiol. Behav. 87, 109-113. doi: 10.1016/j.physbeh.2005.09.011

Pignatelli, A., Ackman, J. B., Vigetti, D., Beltrami, A. P., Zucchini, S., and Belluzzi, O. (2009). A potential reservoir of immature dopaminergic replacement neurons in the adult mammalian olfactory bulb. Pflugers Arch. 457, 899-915. doi: 10.1007/s00424-008-0535-0

Pignatelli, A., Borin, M., Fogli Iseppe, A., Gambardella, C., and Belluzzi, O. (2013). The h-current in periglomerular dopaminergic neurons of the mouse olfactory bulb. PLoS One 8:e56571. doi: 10.1371/journal.pone. 0056571

Pignatelli, A., Fogli Iseppe, A., Gambardella, C., Borin, M., and Belluzzi, O. (2012). "Pacemaker currents in dopaminergic neurons of the mice olfactory bulb," in Electrophysiology-From Plants to Heart, ed. S. Oraii (Rijeka: InTech), 25-50.

Pignatelli, A., Kobayashi, K., Okano, H., and Belluzzi, O. (2005). Functional properties of dopaminergic neurones in the mouse olfactory bulb. J. Physiol. 564, 501-514. doi: 10.1113/jphysiol.2005.084632

Puopolo, M., Bean, B. P., and Raviola, E. (2005). Spontaneous activity of isolated dopaminergic periglomerular cells of the main olfactory bulb. J. Neurophysiol. 94, 3618-3627. doi: 10.1152/jn.00225.2005

Rochefort, C., Gheusi, G., Vincent, J. D., and Lledo, P. M. (2002). Enriched odor exposure increases the number of newborn neurons in the adult olfactory bulb and improves odor memory. J. Neurosci. 22, 2679-2689.

Rodríguez-Traver, E., Solís, O., Díaz-Guerra, E., Ortiz, Ó., Vergaño-Vera, E., Méndez-Gómez, H. R., et al. (2016). Role of Nurr1 in the generation and differentiation of dopaminergic neurons from stem cells. Neurotox. Res. 30, 14-31. doi: 10.1007/s12640-015-9586-0

Saino-Saito, S., Sasaki, H., Volpe, B. T., Kobayashi, K., Berlin, R., and Baker, H. (2004). Differentiation of the dopaminergic phenotype in the olfactory system of neonatal and adult mice. J. Comp. Neurol. 479, 389-398. doi: 10.1002/cne. 20320

Sawada, M., Kaneko, N., Inada, H., Wake, H., Kato, Y., Yanagawa, Y., et al. (2011). Sensory input regulates spatial and subtype-specific patterns of neuronal turnover in the adult olfactory bulb. J. Neurosci. 31, 11587-11596. doi: 10.1523/JNEUROSCI.0614-11.2011

Sawamoto, K., Nakao, N., Kobayashi, K., Matsushita, N., Takahashi, H., Kakishita, K., et al. (2001). Visualization, direct isolation and transplantation of midbrain dopaminergic neurons. Proc. Natl. Acad. Sci. US A 98, 6423-6428. doi: $10.1073 /$ pnas. 111152398

Schoenfeld, T., Marchand, J. E., and Macrides, F. (1985). Topographic organization of tufted cell axonal projections in the hamster main olfactory bulb: an intrabulbar associational system. J. Comp. Neurol. 235, 503-518. doi: 10.1002/cne.902350408

Serguera, C., Triaca, V., Kelly-Barrett, J., Banchaabouchi, M. A., and Minichiello, L. (2008). Increased dopamine after mating impairs olfaction and prevents odor interference with pregnancy. Nat. Neurosci. 11, 949-956. doi: 10.1038/nn.2154

Stone, D. M., Grillo, M., Margolis, F. L., Joh, T. H., and Baker, H. (1991). Differential effect of functional olfactory bulb deafferentation on tyrosine hydroxylase and glutamic acid decarboxylase messenger RNA levels in rodent juxtaglomerular neurons. J. Comp. Neurol. 311, 223-233. doi: 10.1002/cne. 903110205

Taylor, T. N., Caudle, W. M., Shepherd, K. R., Noorian, A., Jackson, C. R., Iuvone, P. M., et al. (2009). Nonmotor symptoms of Parkinson's disease revealed in an animal model with reduced monoamine storage capacity. J. Neurosci. 29, 8103-8113. doi: 10.1523/JNEUROSCI.1495-09. 2009

Tillerson, J. L., Caudle, W. M., Parent, J. M., Gong, C., Schallert, T., and Miller, G. W. (2006). Olfactory discrimination deficits in mice lacking the dopamine transporter or the D2 dopamine receptor. Nat. Commun. 172, 97-105. doi: 10.1016/j.bbr.2006.04.025

Toida, K., Kosaka, K., Aika, Y., and Kosaka, T. (2000). Chemically defined neuron groups and their subpopulations in the glomerular layer of the rat main olfactory bulb. IV. Intraglomerular synapses of tyrosine hydroxylaseimmunoreactive neurons. Neuroscience 101, 11-17. doi: 10.1016/s03064522(00)00356-0

Urbani, A., and Belluzzi, O. (2000). Riluzole inhibits the persistent sodium current in mammalian CNS neurons. Eur. J. Neurosci. 12, 3567-3574. doi: 10.1046/j. 1460-9568.2000.00242.x

Ventura, R. E., and Goldman, J. E. (2007). Dorsal radial glia generate olfactory bulb interneurons in the postnatal murine brain. J. Neurosci. 27, 4297-4302. doi: 10.1523/JNEUROSCI.0399-07.2007

Vergaño-Vera, E., Díaz-Guerra, E., Rodríguez-Traver, E., Méndez-Gomez, H. R., Solís, Ó., Pignatelli, J., et al. (2015). Nurr1 blocks the mitogenic effect of FGF-2 and EGF, inducing olfactory bulb neural stem cells to adopt dopaminergic and dopaminergic-GABAergic neuronal phenotypes. Dev. Neurobiol. 75, 823-841. doi: 10.1002/dneu.22251

Vergaño-Vera, E., Yusta-Boyo, M. J., de Castro, F., Bernad, A., de Pablo, P. F., and Vicario-Abejón, C. (2006). Generation of GABAergic and dopaminergic 
interneurons from endogenous embryonic olfactory bulb precursor cells. Development 133, 4367-4379. doi: 10.1242/dev.02601

Wachowiak, M., and Cohen, L. B. (1999). Presynaptic inhibition of primary olfactory afferents mediated by different mechanisms in lobster and turtle. J. Neurosci. 19, 8808-8817.

Wachowiak, M., McGann, J. P., Heyward, P. M., Shao, Z., Puche, A. C., and Shipley, M. T. (2005). Inhibition of olfactory receptor neuron input to olfactory bulb glomeruli mediated by suppression of presynaptic calcium influx. J. Neurophysiol. 94, 2700-2712. doi: 10.1152/jn.00 286.2005

Wei, C. J., Linster, C., and Cleland, T. A. (2006). Dopamine $\mathrm{D}_{2}$ receptor activation modulates perceived odor intensity. Behav. Neurosci. 120, 393-400. doi: $10.1037 / 0735-7044.120 .2 .393$

Wilson, D. A., and Sullivan, R. M. (1995). The D2 antagonist spiperone mimics the effects of olfactory deprivation on mitral/tufted cell odor response patterns. J. Neurosci. 15, 5574-5581.

Wilson, D. A., and Wood, J. G. (1992). Functional consequences of unilateral olfactory deprivation: time-course and age sensitivity. Neuroscience 49, 183-192. doi: 10.1016/0306-4522(92) 90086-h

Winner, B., Cooper-Kuhn, C. M., Aigner, R., Winkler, J., and Kuhn, H. G. (2002). Long-term survival and cell death of newly generated neurons in the adult rat olfactory bulb. Eur. J. Neurosci. 16, 1681-1689. doi: 10.1046/j.1460-9568.2002. 02238.x
Yamaguchi, M., and Mori, K. (2005). Critical period for sensory experiencedependent survival of newly generated granule cells in the adult mouse olfactory bulb. Proc. Natl. Acad. Sci. U S A 102, 9697-9702. doi: 10.1073/pnas. 0406082102

Young, K. M., Fogarty, M., Kessaris, N., and Richardson, W. D. (2007). Subventricular zone stem cells are heterogeneous with respect to their embryonic origins and neurogenic fates in the adult olfactory bulb. J. Neurosci. 27, 8286-8296. doi: 10.1523/JNEUROSCI.0476-07.2007

Zaborszky, L., Carlsen, J., Brashear, H. R., and Heimer, L. (1986). Cholinergic and GABAergic afferents to the olfactory bulb in the rat with special emphasis on the projection neurons in the nucleus of the horizontal limb of the diagonal tract. J. Comp. Neurol. 243, 488-509. doi: 10.1002/cne. 902430405

Conflict of Interest Statement: The authors declare that the research was conducted in the absence of any commercial or financial relationships that could be construed as a potential conflict of interest.

Copyright $\odot 2017$ Pignatelli and Belluzzi. This is an open-access article distributed under the terms of the Creative Commons Attribution License (CC BY). The use, distribution and reproduction in other forums is permitted, provided the original author(s) or licensor are credited and that the original publication in this journal is cited, in accordance with accepted academic practice. No use, distribution or reproduction is permitted which does not comply with these terms. 